\title{
Classification and Localization of the Adductor Hiatus: A Cadaver Study
}

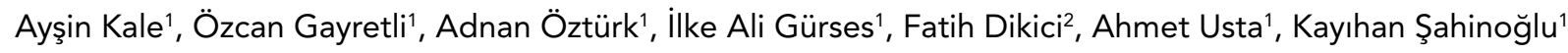 \\ 'Department of Anatomy, Faculty of Medicine, İstanbul University, istanbul, Turkey \\ ${ }^{2}$ Department of Orthopaedics and Traumatology, Faculty of Medicine, Istanbul University, Istanbul, Turkey
}

\begin{abstract}
Objective: To determine not only the vertical but also horizontal localization of the adductor hiatus $(\mathrm{AH})$ and classify its shape and structure macroscopically. Material and Methods: Forty lower extremities were dissected to expose the AH. Its shape and structure were macroscopically noted, and the AH was classified into four types. For determining the localization, measurements were made with digital calipers.

Results: Twenty-four oval fibrous types, 12 oval muscular types, 2 bridging fibrous types and 2 bridging muscular types of AH were determined. For the horizontal localization of $\mathrm{AH}$, the apex of the $\mathrm{AH}$ was determined to be located medial to the vertical line between the midpoint of the interepicondylar distance and the line which was drawn transversely from the apex of the $\mathrm{AH}$, in all of the cadavers. For the vertical one, the apex of the $\mathrm{AH}$ was located in the middle third of the femur length in 14 thighs, and in the remaining 26 ones, the apex of the $\mathrm{AH}$ was located in the distal third of the femur length.

Conclusion: Adductor hiatus was classified according to its shape and structure for the first time. Moreover, the localization of the AH was practically defined, in order not to harm the popliteal artery and vein.
\end{abstract}

Key Words: Adductor hiatus, adductor canal outlet syndrome, femoropopliteal occlusion, adductor magnus muscle

Received: 05.01.2012

Accepted: 10.04 .2012

\section{Introduction}

The adductor hiatus $(\mathrm{AH})$ can be described as an opening in the aponeurotic distal attachment of adductor magnus muscle, which transmits the femoral artery and vein from the adductor canal in the thigh to the popliteal fossa (1). The adductor magnus muscle is also interrupted by a series of osseo-aponeurotic openings, and these openings transmit the perforating branches and the termination of the profunda femoris artery (2).

The majority of femoropopliteal occlusions are located distally in the thigh (3-7). More specifically, occlusions of the femoropopliteal region have a high incidence in the adductor hiatus region $(6,7)$. Evaluating the previous studies, Watt (7) reported that $60-70 \%$ of all femoropopliteal occlusions were located in the adductor region. Using Duplex ultrasound, Scholten et al. (6) found that $72 \%$ of occlusions of the femoropopliteal region were localized at the level of the adductor canal hiatus.

The exact mechanism for causing occlusions at the adductor canal hiatus has not been well esablished yet. Besides general atherogenic causes, the high incidence of occlusions is considered to be due to local anatomic factors $(5,6,8,9)$. Several theories for these factors may include direct mechanical damage to the vessel wall due to traction or compression $(4-6,10)$, unfavourable haemodynamic circumstances such as frequent branching or an S-shaped configuration of the femoral and popliteal arteries (7), repeated trauma created by the pulsatile movements of the arterial wall where it lies in intimate contact with the aponeurosis of the adductor magnus muscle $(10,11)$, and the influence of knee flexion on atherogenesis in the adductor and popliteal region as the femoral and popliteal arteries become tortuous during knee flexion (4, $7,8)$. Moreover, in the hiatal region there is a transition zone from a fixed position in the adductor canal to a freely movable position in the fatty tissue of the popliteal fossa and, during muscle action and leg movement, shear forces may stress the vessel wall in the transition zone $(6,11)$. Contrarily, Wensing et al. (9) asserted that a relationship between localization of atherosclerotic lesions and haemodynamics was more likely and they reported that early atherosclerotic lesions revealed no apparent relation with surrounding structures and added that a prefential helical distribution had been observed in the atherosclerotic lesions.

However, neither the exact localization nor the shape and structure of the $\mathrm{AH}$ have been studied in detail yet. Knowledge of these factors might explain why only particular people are exposed to thrombosis of the femoral artery at the level of the $\mathrm{AH}$. Consequently, the purpose of this study was to determine not only the vertical but also the horizontal localization of the $\mathrm{AH}$ in the thigh and classify its shape and structure macroscopically. 


\section{Material and Methods}

Forty lower extremities of 20 embalmed cadavers were dissected to expose the $\mathrm{AH}$ and the shape and structure of each $\mathrm{AH}$ were macroscopically noted. The cadavers did not have malformations or surgical operations of hip and femur. According to its shape, the adductor hiatus was firstly classified into two groups: the oval type and the bridging type. The ones which were oval in shape were classified as the oval type and the ones which crossed over the popliteal artery and vein like a bridge were classified as the bridging type. Afterwards, the structure of the fibers which formed the borders of the adductor hiatus was noted, and subgroups (fibrous and muscular) were formed according to these. Finally, the $\mathrm{AH}$ was classified into four types: oval fibrous, oval muscular, bridging fibrous and bridging muscular.

In order to determine the localization of the $\mathrm{AH}$, we made some measurements with digital calipers. Firstly, some landmarks were defined and several lines were drawn between these landmarks for the measurements (Figure 1). The distance between the medial and lateral epicondyles of the femur was measured and the midpoint of this distance was marked. Then

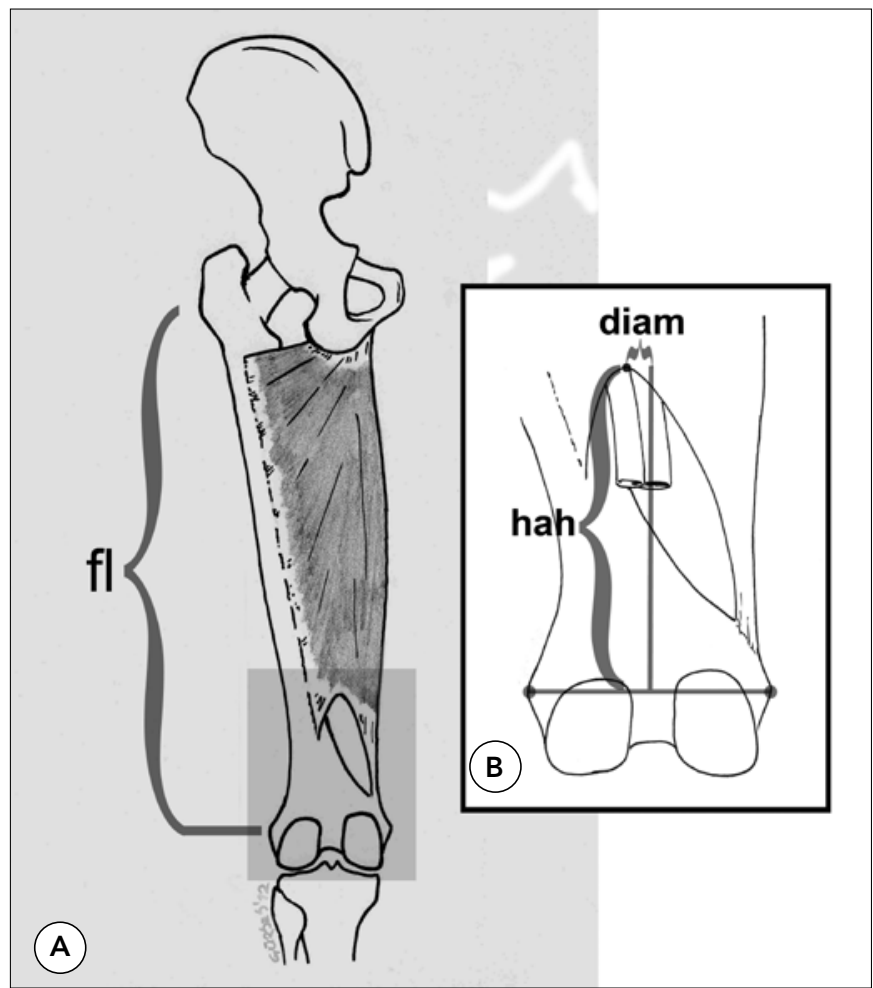

Figure 1. The illustration showing the measurements taken related with the localization of the adductor hiatus. A) left thigh from behind, B) inlet showing close up view of the $\mathrm{AH}$ and the measurements performed to find the localization of the apex of the $\mathrm{AH}$. fl: femur length (the distance between the highest palpable point of the greater trochanter and the horizontal continuation of the interepicondylar distance), hah: height of the adductor hiatus, diam: distance between the apex and the vertical line beginning from the midpoint of the interepicondylar line the distance between the midpoint of the interepicondylar distance and the line which was drawn transversely from the apex of the $\mathrm{AH}$ (height of the $\mathrm{AH}$ ) was measured. To define a proportional relation of the vertical localization of the $\mathrm{AH}$ according to the length of the femur, the distance between the line drawn transversely from the highest palpable point of the greater trochanter and the horizontal continuation of the interepicondylar distance was measured as the femur length. Afterwards, the height of the $\mathrm{AH}$ was proportioned to the femur length and the localization of the apex of the $\mathrm{AH}$ was noted to be found either at the proximal third, middle third or distal third of the femur length. To define the horizontal localization of the $\mathrm{AH}$, the distance between the line which was drawn vertically upwards from the midpoint of the interepicondylar distance and apex of the $\mathrm{AH}$ was measured. The position of the apex of the $\mathrm{AH}$, being either medial or lateral to the vertical line between midpoint of interepicondylar distance, and the line which was drawn transversely from apex of $\mathrm{AH}$, were noted.

The popliteal artery and vein leaving through the adductor hiatus were examined in each thigh and their relationship to each other were noted. Moreover, the adductor magnus muscle was examined for the presence of perforating arteries. Furthermore, the insertion of the medial part and lateral part of the adductor magnus muscle were examined.

\section{Results}

In 36 thighs, the $\mathrm{AH}$ was oval in shape. Of these 36 thighs, 24 thighs had oval fibrous type $\mathrm{AH}$ (Figure 2). The remaining 12 had oval muscular type $\mathrm{AH}$ (Figure 3). In 4 thighs, the $\mathrm{AH}$ had a bridging shape. Two of these 4 thighs had bridging fibrous $\mathrm{AH}$ (Figure 4) and the other two thighs had bridging muscular $\mathrm{AH}$ (Figure 5). Of a total of 20 cadavers, the $\mathrm{AH}$ did not have the same type in both sides except in 2 cadavers.

The mean distance between medial and lateral epicondyles of the femur was measured as $88.5 \mathrm{~mm}$ (range from 76.3 to $94.7 \mathrm{~mm}$ ). In relation to the vertical localization, the mean distance between the midpoint of the interepicondylar distance and the line which was drawn transversely from the apex of the $\mathrm{AH}$ (height of the $\mathrm{AH}$ ) was found as $119.6 \mathrm{~mm}$ (range from 72 to $170.4 \mathrm{~mm}$ ). The femur length was found as a mean of $369.2 \mathrm{~mm}$ (range from 334 to $445 \mathrm{~mm}$ ). In 14 thighs, the apex of the $\mathrm{AH}$ was located in the middle third of the femur length and in the remaining 26 , the apex of the $\mathrm{AH}$ was located in the distal third of the femur length.

In relation to the horizontal localization, the mean distance between the line which was drawn vertically upwards from the midpoint of the interepicondylar distance and the apex of the $\mathrm{AH}$ was measured as $7.94 \mathrm{~mm}$ (range from 2.2 to $17.4 \mathrm{~mm}$ ). In all of the cadavers, the apex of the $\mathrm{AH}$ was determined to exist medial to the vertical line between the midpoint of the interepicondylar distance and the line which was drawn transversely from apex of the $\mathrm{AH}$.

The numerical and characteristic data of all cadavers are summarized in Table 1.

The popliteal artery and popliteal vein, leaving through the adductor hiatus, were present in all thighs. In all of the 


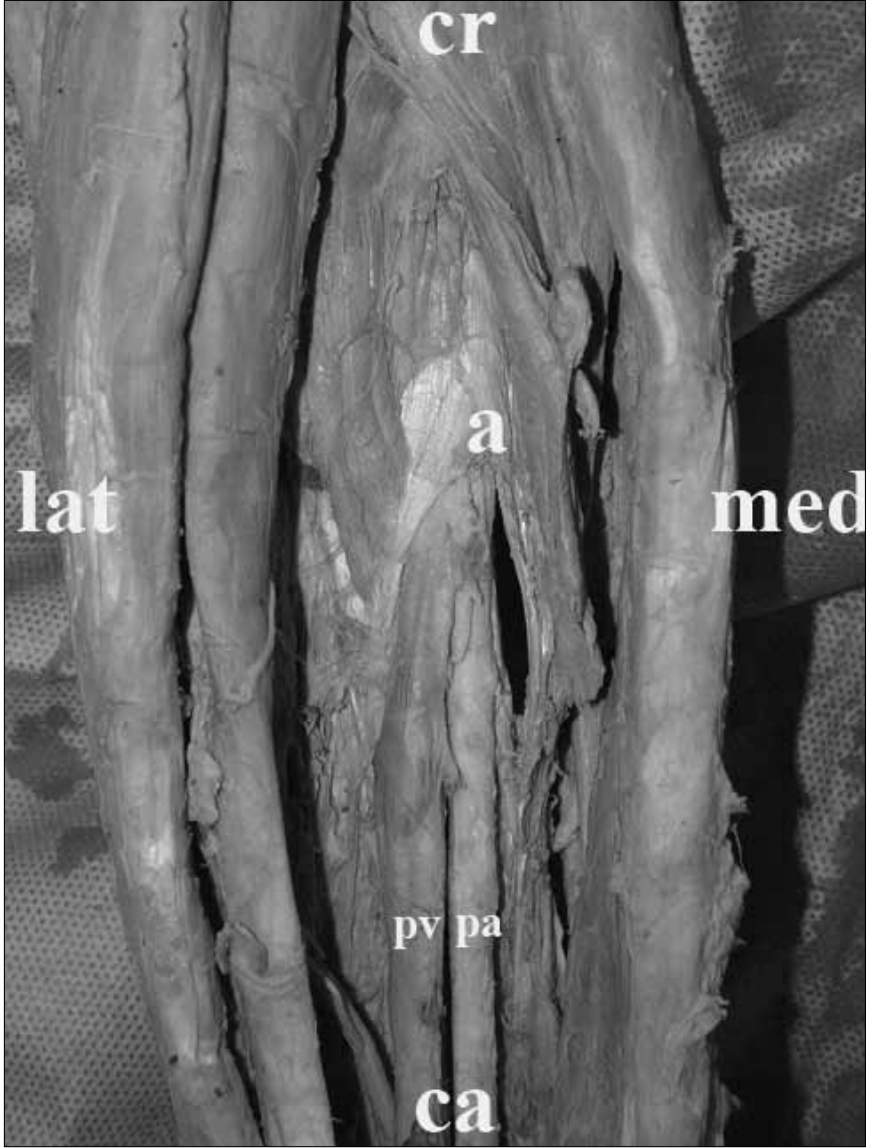

Figure 2. Oval fibrous type adductor hiatus. a: apex of the adductor hiatus, cr: cranial, ca:caudal, med: medial, lat: lateral, pa: popliteal artery, pv: popliteal vein

cadavers, the popliteal vein was lateral to the popliteal artery. The adductor magnus muscle was always perforated by several perforating arteries above the adductor hiatus regardless of the type of the adductor hiatus (Figure 3 ). The medial part of the adductor magnus muscle was always attached to the adductor tubercle of the femur, and its lateral part was always attached to the proximal part of the medial supracondylar line, regardless of the type of adductor hiatus, either fibrous or muscular.

\section{Discussion}

The compression of the femoral artery at the $\mathrm{AH}$ is a well-recognized entity and the majority of lower limb arterial occlusions have been located in the distal third of the thigh (4-9, 12-14). Related to this localization, a rare entity, the adductor canal outlet syndrome has also been described $(12,15,16)$. This syndrome involves thrombosis of the femoral artery at the level of the $\mathrm{AH}$. It occurs as a result of microtrauma to the intima of the vessel due to a scissor-like compression from the vastus medialis or adductor magnus tendons. A hypertrophied band or portion of the tendon is usually responsible for the compression. Calf claudication, numbness, parasthesias and coolness of the foot, lack or diminishing of the popliteal and pedal pulses due to the exist-

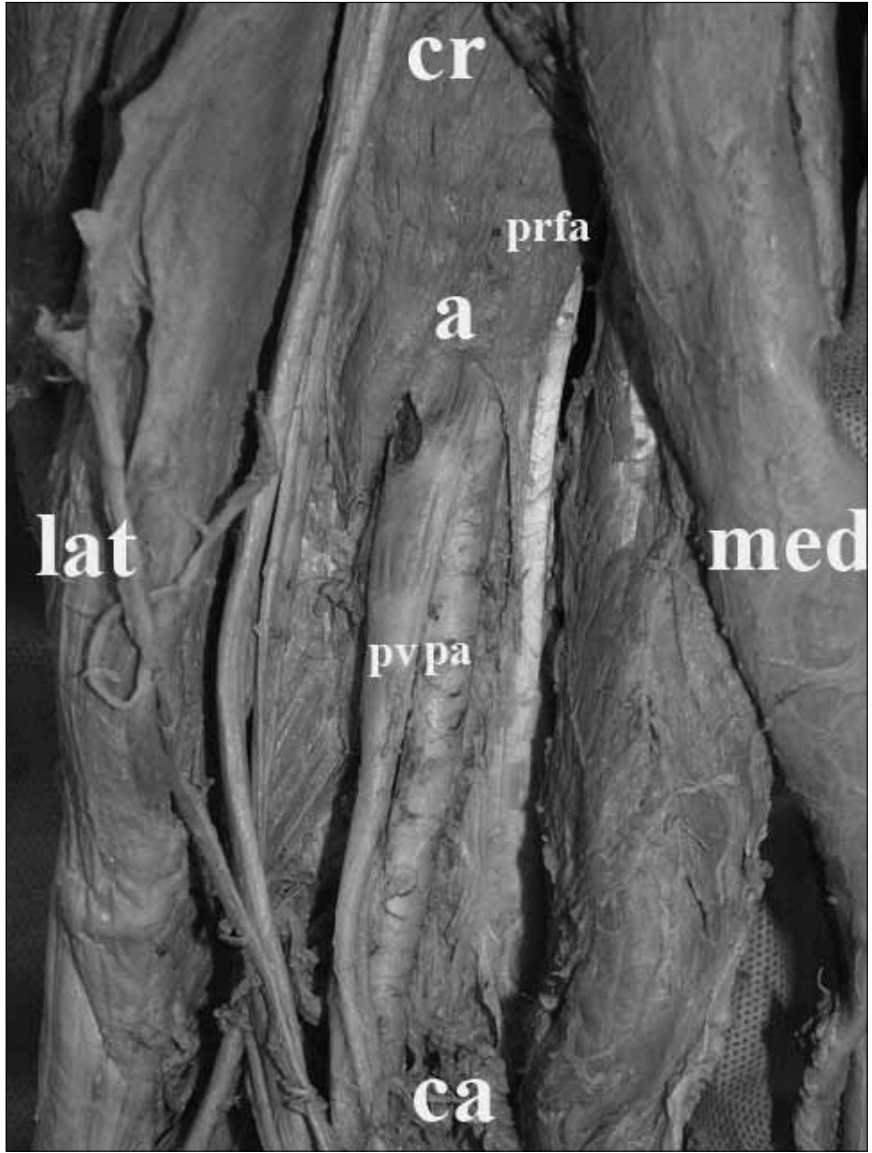

Figure 3. Oval muscular type adductor hiatus. a: apex of the adductor hiatus, cr: cranial, ca:caudal, med:medial, lat:lateral, pa: popliteal artery, pv: popliteal vein, prfa: perforating artery

ing occluding thrombus can be observed in patients having adductor canal outlet syndrome. In these cases, angiography shows segmental occlusion of the femoral artery at the level of the $\mathrm{AH}$. The symptoms may begin suddenly or in a gradual way. Mostly, initiation of a running program or a twisting injury while cross-country skiing have been held responsible for $f$ the onset of symptoms $(16,17)$. An awareness of the relationship of these activities to acute intimal injury and thrombosis is key to providing effective treatment and saving limbs that would otherwise be lost $(12,15)$. Treatment consists of surgical excision of the compressing tendinous band along with saphenous vein bypass grafting $(16,17)$.

Although thrombosis of the femoral artery at the level of the $\mathrm{AH}$ has been well defined, neither the exact localization nor shape of the $\mathrm{AH}$ has been clarified by any surgical, radiologic or postmortem observations.

A few cadaver studies report only the vertical localization of the $\mathrm{AH}(18,19)$. Olson and Holt (19) measured the distance from the adductor tubercle to the $\mathrm{AH}$ in both lower extremities of 24 skeletally mature cadavers and they reported that this distance ranged from 80 to $135 \mathrm{~mm}$ (mean 100) and they stated that the area up to $80 \mathrm{~mm}$ proximal to the adductor tubercle, appeared to be a safe interval for avoiding vascular structures with percutaneous or limited open surgeries of the 


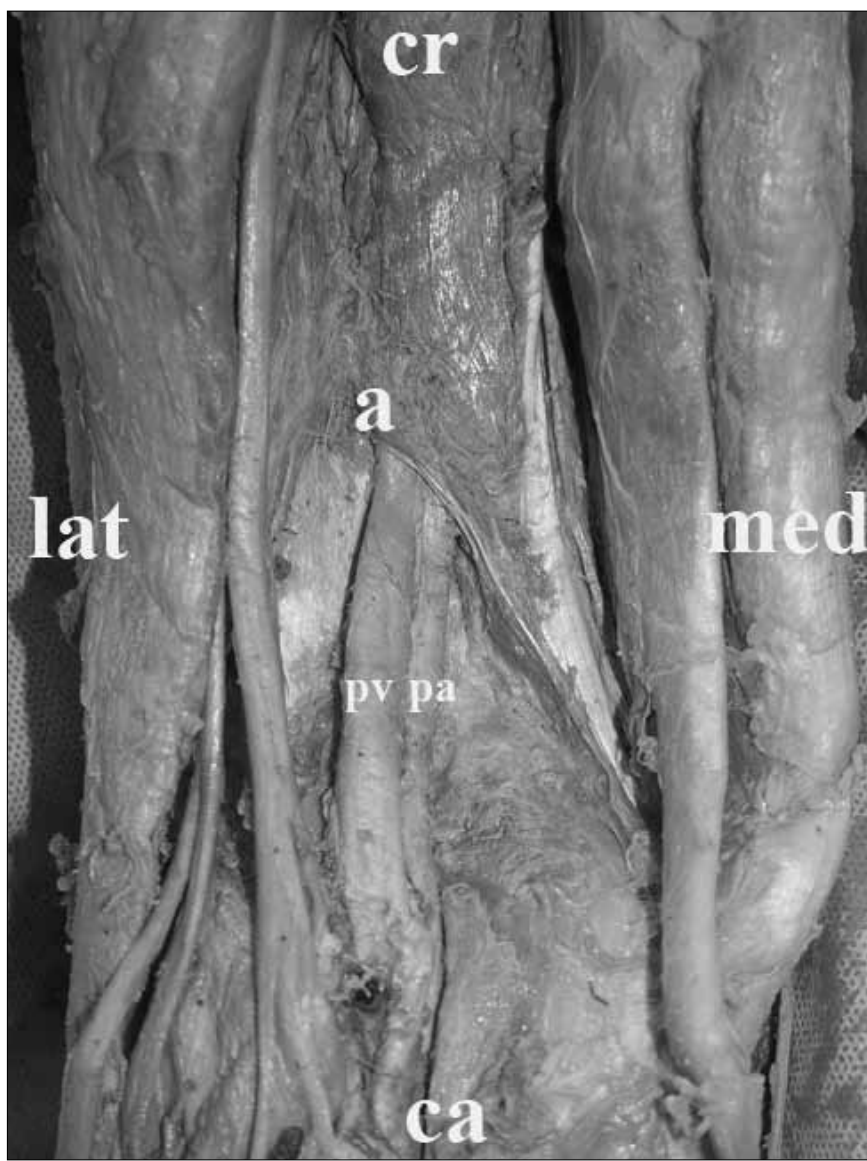

Figure 4. Bridging fibrous type adductor hiatus. a: apex of the adductor hiatus, cr: cranial, ca:caudal, med: medial, lat: lateral, pa: popliteal artery, pv: popliteal vein

medial aspect of the distal femur. Checroun et al. (18) measured the distance from the adductor tubercle to the proximal most point of the $\mathrm{AH}$ and found that it ranged from 132 to $180 \mathrm{~mm}$. In the present study, the mean distance between the midpoint of the interepicondylar distance and the line which was drawn transversely from the apex of the $\mathrm{AH}$ was found as $119.6 \mathrm{~mm}$ (range from 72 to $170.4 \mathrm{~mm}$ ). Consequently, as in Olson and Holt's results (19), the region over the distance 72 $\mathrm{mm}$ proximal to the midpoint of the interepicondylar distance seems to be safe for the popliteal artery and vein during surgical procedures of the distal femur. The importance of this safe interval was also emphasized by Scheibel et al. (20). In their study related with total knee replacement via a subvastus approach, they reported that the proximal limitation for the mobilization was the $\mathrm{AH}$, in order not to damage the femoral artery and vein (20).

Two ultrasonographic studies were also performed to localize the $\mathrm{AH}(5,6)$. In 1989, Scholten et al. (5) used external sonography to localize the $\mathrm{AH}$. According to them, the exact location of the adductor canal hiatus was defined as the site where the cross section of the femoral artery was at the level of the two echogenic lines that represented the continuation of the adductor fascia on either side of the defect. They also reported that the location of the $\mathrm{AH}$ varied from $80-130 \mathrm{~mm}$ (mean $100 \mathrm{~mm}$ ) cranial to patella in 16 legs of eight healthy

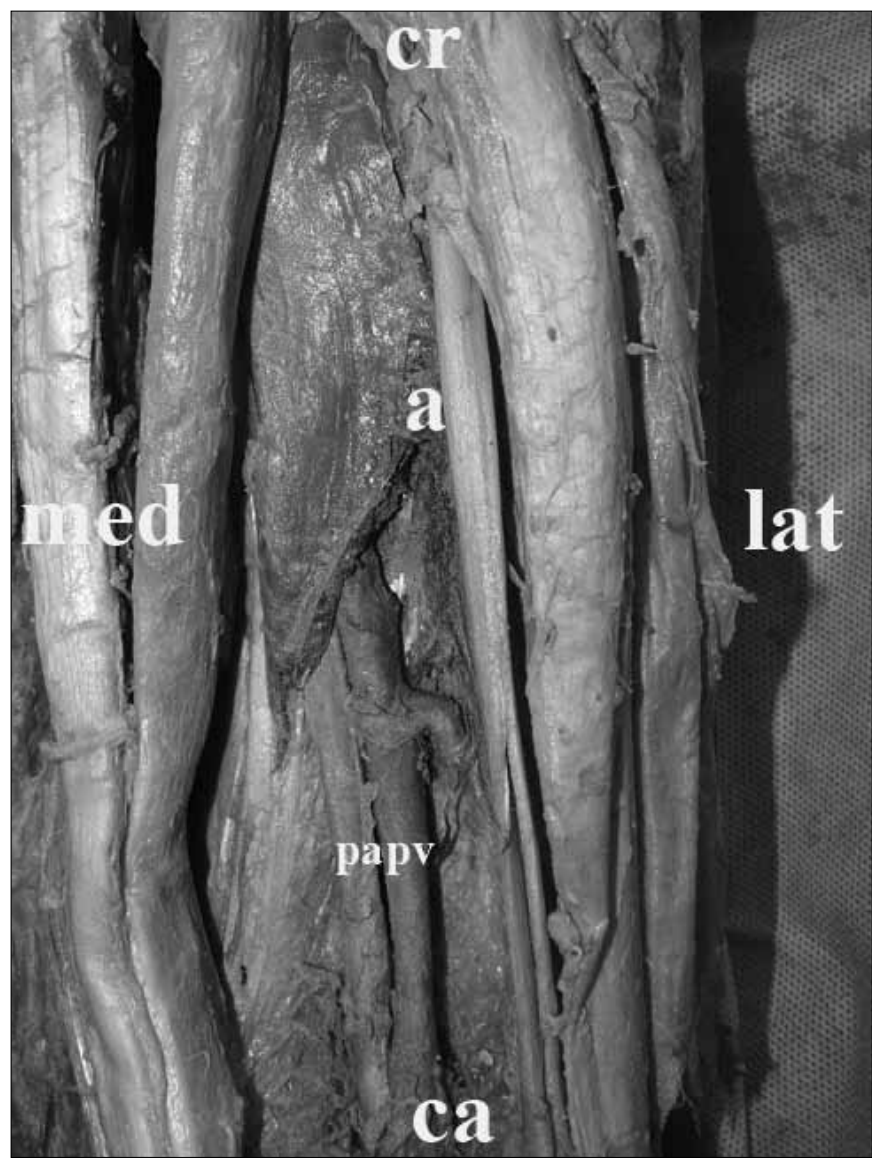

Figure 5. Bridging muscular type adductor hiatus. a: apex of the adductor hiatus, cr: cranial, ca: caudal, med: medial, lat: lateral, pa: popliteal artery, pv: popliteal vein

volunteers (5). In 1993, Scholten et al. (6) used Duplex ultrasound to locate the level of femoropopliteal occlusions with respect to the level of the $\mathrm{AH}$ in 50 patients. They reported that the location of the $\mathrm{AH}$ varied from $70-150 \mathrm{~mm}$ (mean 105 $\mathrm{mm}$ ) cranial to the upper border of the patella. They added that $72 \%$ of occlusions showed a relation with the hiatus (6). The results of the present study indicating the vertical localization of the $\mathrm{AH}$ were compatible with the results of these two ultrasonographic studies. Related with ultrasonography of the $\mathrm{AH}$, The et al. (13) used intravascular sonography to differentiate between residual stenosis due to residual plaque and that due to extrinsic compression of the wall of the femoral artery near the $\mathrm{AH}$.

The most important finding of the present study was the classification of four different types of $\mathrm{AH}$ according to its shape for the first time and the structure and localization of the $\mathrm{AH}$, not only vertically but also horizontally. The most frequent shape of the $\mathrm{AH}$ was found to be the oval fibrous one. For its horizontal localization, the apex of the $\mathrm{AH}$ was localized medial to the vertical line between the midpoint of interepicondylar distance and the line which was drawn transversely from the apex of the $\mathrm{AH}$ in all of the cadavers. For its vertical localization, the apex of the $\mathrm{AH}$ was most frequently localized in the distal third of the femur length. 
Table 1. Shows the numerical and characteristic data of all cadavers

\begin{tabular}{|c|c|c|c|c|c|c|}
\hline $\begin{array}{l}\text { Cadaver no } \\
\text { \& side }\end{array}$ & $\begin{array}{l}\text { Distance } \\
\text { between } \\
\text { medial and } \\
\text { lateral } \\
\text { epicondyles } \\
\text { of femur }\end{array}$ & $\begin{array}{c}\text { Distance } \\
\text { between } \\
\text { midpoint of } \\
\text { interepicondylar } \\
\text { distance and the } \\
\text { line which was } \\
\text { drawn } \\
\text { transversely } \\
\text { from apex of } \\
\text { adductor hiatus }\end{array}$ & $\begin{array}{l}\text { Distance } \\
\text { between the line } \\
\text { which was } \\
\text { drawn vertically } \\
\text { upwards from } \\
\text { the midpoint of } \\
\text { interepicondylar } \\
\text { distance and } \\
\text { apex of } \\
\text { adductor hiatus }\end{array}$ & $\begin{array}{l}\text { The femur } \\
\text { length }\end{array}$ & $\begin{array}{l}\text { Localization } \\
\text { of apex of } \\
\text { adductor } \\
\text { hiatus; either } \\
\text { existing in } \\
\text { the middle or } \\
\text { distal third of } \\
\text { the femur } \\
\text { length }\end{array}$ & $\begin{array}{c}\text { Type of adductor } \\
\text { hiatus }\end{array}$ \\
\hline No: 1 right & 89.4 & 156 & 14.8 & 348 & Middle & Oval fibrous \\
\hline No: 1 left & 93.5 & 170.4 & 17.4 & 349 & Middle & Oval fibrous \\
\hline No: 2 right & 85.4 & 135 & 9.6 & 354 & Middle & Oval fibrous \\
\hline No: 2 left & 82.0 & 148 & 16.9 & 355 & Middle & Oval fibrous \\
\hline No: 3 right & 76.3 & 105 & 12.2 & 344 & Distal & Oval fibrous \\
\hline No: 3 left & 77.1 & 110 & 14.7 & 343 & Distal & Oval fibrous \\
\hline No: 4 right & 91.5 & 115 & 15.3 & 372 & Distal & Bridging muscular \\
\hline No: 4 left & 90.3 & 125 & 10.3 & 370 & Distal & Oval fibrous \\
\hline No: 5 right & 94.0 & 110 & 8.8 & 383 & Distal & Oval fibrous \\
\hline No: 5 left & 94.7 & 107 & 9.9 & 382 & Distal & Oval fibrous \\
\hline No: 6 right & 90.9 & 130 & 7.9 & 400 & Distal & Oval fibrous \\
\hline No: 6 left & 92.3 & 95 & 10.6 & 401 & Distal & Oval fibrous \\
\hline No: 7 right & 83.3 & 131 & 5.8 & 388 & Middle & Oval muscular \\
\hline No: 7 left & 83.1 & 125 & 5.7 & 386 & Middle & Oval muscular \\
\hline No: 8 right & 85.4 & 128 & 6.7 & 363 & Middle & Oval muscular \\
\hline No: 8 left & 84.4 & 129 & 7.9 & 365 & Middle & Oval muscular \\
\hline No: 9 right & 87.9 & 123 & 2.2 & 371 & Distal & Oval fibrous \\
\hline No: 9 left & 87.0 & 130 & 5.7 & 370 & Middle & Oval fibrous \\
\hline No: 10 right & 91.7 & 102 & 5.8 & 335 & Distal & Oval fibrous \\
\hline No: 10 left & 91.8 & 104 & 6 & 334 & Distal & Oval fibrous \\
\hline No: 11 right & 90.9 & 106 & 5.4 & 443 & Distal & Oval muscular \\
\hline No: 11 left & 94.7 & 108 & 8.2 & 445 & Distal & Oval muscular \\
\hline No: 12 right & 91.9 & 88 & 3 & 336 & Distal & Oval fibrous \\
\hline No: 12left & 88.7 & 72 & 6.9 & 334 & Distal & Bridging muscular \\
\hline No: 13 right & 85.5 & 108 & 4.9 & 362 & Distal & Bridging fibrous \\
\hline No: 13 left & 84.4 & 118 & 6.7 & 365 & Middle & Bridging fibrous \\
\hline No: 14 right & 89.9 & 121 & 4.5 & 371 & Distal & Oval fibrous \\
\hline No: 14 left & 90.8 & 111 & 5.6 & 372 & Distal & Oval fibrous \\
\hline No: 15 right & 85.5 & 130 & 7.2 & 368 & Middle & Oval fibrous \\
\hline No: 15 left & 86.6 & 125 & 6.4 & 366 & Middle & Oval fibrous \\
\hline No: 16 right & 89.8 & 128 & 5.6 & 355 & Middle & Oval muscular \\
\hline No: 16 left & 86.3 & 112 & 4.8 & 353 & Distal & Oval muscular \\
\hline No: 17 right & 91.0 & 136 & 5.2 & 369 & Middle & Oval fibrous \\
\hline No: 17 left & 90.4 & 131 & 6.2 & 370 & Distal & Oval fibrous \\
\hline No: 18 right & 91.4 & 120 & 7.8 & 348 & Distal & Oval muscular \\
\hline No: 18 left & 87.2 & 119.1 & 6.9 & 346 & Distal & Oval muscular \\
\hline No: 19 right & 92.0 & 115 & 6.9 & 374 & Distal & Oval muscular \\
\hline No: 19 left & 94.2 & 116 & 7.4 & 375 & Distal & Oval muscular \\
\hline No: 20 right & 88.4 & 122 & 6.6 & 403 & Distal & Oval fibrous \\
\hline No: 20 left & 86.6 & 120 & 6.8 & 401 & Distal & Oval fibrous \\
\hline Average results & 88.5 & 119.6 & 7.94 & 369.2 & & \\
\hline
\end{tabular}




\section{Conclusion}

The $\mathrm{AH}$ was classified according to its shape and structure in the present study for the first time. Moreover, the localization of the AH was practically defined, in order not to cause harm to the popliteal artery and vein during the surgical procedures of the distal femur. Furthermore, as the $\mathrm{AH}$ is one of the two principal sites for femoropopliteal occlusions, the localization of the $\mathrm{AH}$ might be a guidline for the treatment of these occlusions for the vascular surgeons.

\section{Conflict of Interest}

No conflict of interest was declared by the authors.

\section{References}

1. Moore KL, Dalley AF. Clinically oriented Anatomy. Lippincott Williams \& Wilkins. 4th edition. 1999.pp.541.

2. Standring S, editor. Gray's Anatomy. Spain: Churchill Livingstone. 39th edition. 2005.pp.1466.

3. McMillan DE. Blood flow and the localization of atherosclerotic plaques. Stroke 1985;16:582-7. [CrossRef]

4. Lindblom A. Arteriosclerosis and arterial thrombosis in the lower limb. Acta Radiol 1950;80:1-80.

5. Scholten FG, Mali WP, Hilen B, van Leeuwen MS. US location of the adductor canal hiatus: a morphologic study. Radiology 1989;172:75-8.

6. Scholten FG, Warnars GA, Mali WP, van Leeuwen MS. Femoropopliteal occlusions and the adductor canal hiatus, Duplex study. Eur J Vasc Surg 1993;7:680-3. [CrossRef]

7. Watt JK. Origin of femoro-popliteal regions. $\mathrm{Br}$ Med J 1965:2:1455-9. [CrossRef]

8. Wensing PJW, Scholten FG, Buijs PC, Hartkamp MJ, Mali WPTM, Hillen B. Arterial tortuosity in the femoropopliteal region during knee flexion: a magnetic resonance angiographic study. J Anat 1995;186:133-9.

9. Wensing PJW, Meiss L, Mali WPTM, Hillen B. Early atherosclerotic lesions spiraling through the femoral artery. Arterioscler Thromb Vasc Biol 1998;18:1554-8. [CrossRef]

10. Dunlop GR, Dos Santos R. Adductor canal thrombosis N Eng J Med 1957:256:557-80.

11. Palma EC. Hemodynamic arteriopathy. Angiology 1959;10:134-43. [CrossRef]

12. Balaji MR, DeWeese JA. Adductor canal outlet syndrome. JAMA 1981;245:167-70. [CrossRef]

13. The SH, Wilson RA, Gussenhoven EJ, Pieterman H, Bom K, Roelandt JR, et al. Extrinsic compression of the superficial femoral artery at the adductor canal: evaluation with intravascular sonography. AJR Am J Roentgenol 1992;159:117-20.

14. Tubbs RS, Loukas M, Shoja MM, Apaydin N, Oakes WJ, Salter EG. Anatomy and potential clinical significance of the vastoadductor membrane. Surg Radiol Anat 2007;29:569-73. [CrossRef]

15. Abela GS. Peripheral vascular disease: Basic diagnostic and therapeutic approaches. Lippincott Williams \& Wilkins. 1st edition.2004.pp.100-1.

16. Cohn SL, Taylor WC. Vascular problems of the lower extremity in athletes. Clin Sports Med 1990;9:449-70.

17. Biemans RG, van Bockel JH. Popliteal artery entrapment syndrome. Surg Gynecol Obstet 1977;144:604-9.

18. Checroun AJ, Mekhail AO, Ebraheim NA, Jackson WT, Yeasting RA. Extensile medial approach to the femur. J Orthop Trauma 1996;10:481-6. [CrossRef]

19. Olson SA, Holt BT. Anatomy of the medial distal femur: a study of the adductor hiatus. J Orthop Trauma 1995;9:63-5. [CrossRef]

20. Scheibel MT, Schmidt W, Thomas M, von Salis-Soglio G. A detailed anatomical description of the subvastus region and its clinical relevance for the subvastus approach in total knee arthroplasty. Surg Radiol Anat 2002;24:6-12. [CrossRef] 